\title{
Regional and temporal changes in bivalve diversity off the south coast of Portugal
}

M. M. Rufino ${ }^{1,2}$, M. B. Gaspar ${ }^{1}$, F. Maynou ${ }^{2}$ and C. C. Monteiro ${ }^{1}$

1 Instituto nacional de Recursos Biológicos, L- IPIMAR, Avenida 5 de Outubro s/n, P-8700-305 Olhão, Portugal. Telf. +351 289700 541, 2 Institut de Ciències del Mar (CSIC), Pg. Marítim de la Barceloneta,7-49, 08003 Barcelona, Spain; mrufino@cripsul.ipimar.pt

Estuarine, Coastal and Shelf Science, 80: 517-528 


\section{Abstract}

From 2000 to 2006, a total of 75 bivalve species were identified, varying from 29 (spring 2001) to 54 species (spring 2005) per year. Seasonal tendencies in diversity varied according to year, thus the interpretation of long-term and regional scales is essential before drawing any conclusions in other studies. Richness and diversity consistently decreased with depth and increased with sediment grain size (from low in very coarse sand to high in coarse silt). Diversity decreased progressively from 3 to 16 $m$ depth, thus the harsher shallower environments (due to waves and tidal air exposure) showed greater diversity than the most stable areas. Communities in finer sediments were more diverse than those in coarser sand. Evenness showed patterns opposite to diversity, overall.

Diversity and evenness maps (produced with multivariate universal kriging), showed that most geographic areas with greater diversity were farther from river outflows and wastewater treatment plants. Two types of geographic pattern were observed: areas with persistently greater bivalve diversity through time and areas that changed locally from year to year. This spatial analysis can be used to establish priority conservation areas for management purposes, and to analyse the persistency of regional diversity patterns. The area with most habitat heterogeneity (Sotavento) corresponded to greatest diversity.

There was a positive relationship between Spisula solida and Chamelea gallina landings and bivalve diversity two years and one year later, respectively. Possibly, local fisheries, by selectively withdrawing the commercial numerically dominant species from the ecosystem, increased diversity one to two years later, as the ecological niches of the dominants are quickly filled by several other species thereby creating a more even community. It was not found any significant impact of local fisheries, on regional scales long term bivalve diversity

Keywords bivalve, biodiversity, multivariate analysis; geographical distribution , time series analysis, macrobenthos; fisheries; geographical coordinates bounding: longitude -9 to $-7.5^{\circ} \mathrm{W}$; latitude: $\sim 37^{\circ} \mathrm{N}$. 


\section{INTRODUCTION}

Spatio-temporal fluctuations in diversity often reflect the state of the benthic ecosystem and its response to different forms of disturbance. Species diversity is required not only for the identification of priority sites for protection, but also for monitoring impacts of human activities, particularly in systems subject to recurring harvest of natural resources, that is, fishing and touristic areas . Most studies on diversity have taken place either at small scales (e.g. bays or headlands) or large scales (e.g. whole ocean or large country) and there has been a paucity of investigations at regional scales (100-1000s of $\mathrm{km})$. Still, it is at this scale that most nations have jurisdiction over their resources and can, therefore, best produce effective conservation measures. Furthermore, generally works are done using only one or two years, so the conclusions do not take into account the temporal variability.

Marine benthic communities are ruled by depth, latitude and longitude. Although these are not environmental factors per se, they represent a conjunction of those, and are often the main structuring forces of the communities. Also, most other environmental factors, such as sediment type, water temperature, $\mathrm{pH}$, (among others) are closely related (and strongly correlated) with depth and the geographic variables. Furthermore, by studying the influence of depth and geographic variables on diversity at regional scales, it is easier to establish natural frontiers to be used in management strategies, for example it permits to establish depth intervals that are prioritary for conservation. The other factor that is crucial in marine benthic communities is sediment type, which importance in bivalves has been well established. The influence of river-mouth proximity and beach exposure/wave action on bivalve diversity is poorly understood, although the few works done indentify those as crucial aspects . Thus, by measuring depth, geographic location, sediment type and having the coordinates of river mouth we can have a global picture of diversity and how it relates with the habitat characteristics. All these variables have the advantage of being presently available or could be easily captured for most marine littoral areas, unlike temperature, $\mathrm{pH}$, organic matter, etc.

Species diversity may be defined as a measure of species composition, in terms of both the number of species and their relative abundances . It is a synthetic biotic index which captures multi-dimensional information relative to the species composition of an assemblage community . Although the numerous indexes produced, Hill series are strongly recommended due to their optimal properties. However, there is a great loss of information when diversity distribution of an entire area is summarized into a couple of values and not mapped thoughtfully. As diversity indexes are spatially structured, showing auto-correlation (similar to most 
biological/ecological measures), geostatistics provide a valuable tool for a fully descriptive analysis over all the area. Ignoring spatial autocorrelation in ecological data can produce misleading results in the analysis . A detailed map of diversity permits to delimit the areas with greater diversity throughout the years (diversity hotspots), and the ones that change in a temporal base. Thus, mapping using kriging allows us to determine whether global trends are observed locally. As yet, geostatistical applications to diversity are scarce .

The impact of fishing activities in biodiversity is a question that has been prioritary in fisheries research. However, most works compare the communities on fishing grounds to those on non fished grounds, providing no temporal or spatial effect, which is crucial for a proper fishing management strategy.

The objective of the present work is to analyse temporal and spatial diversity of bivalves off the south coast of Portugal, from 2000 to 2006, and to relate the observed patterns to depth, sediment characteristics, season, proximity of river outflows and of wastewater treatment plants. The effects of fishing effort and fisheries landings on bivalve diversity were also analysed.

\section{Material AND MEthods}

\subsection{Sampling}

Bivalve fishing surveys were carried out from 2000 to 2006, during both Spring/Summer and Autumn/Winter, except in 2003 (only spring was sampled) and 2004 (only autumn was sampled), with the RV Tellina (17.5 m length). In each haul, both a clam dredge (port side, 20-mm teeth) and a razor-clam dredge (starboard side, 35-mm teeth) both with 64-cm mouth opening were used simultaneously.

Sampling was carried out along 108 transects perpendicular to the coast (Fig. 1). Two to three samples were taken at each transect, in different depths. Depths considered were A: $3 \mathrm{~m}$, B: 4.8 m, C: 6.6 m, D: 8.4 m, E: 10.2 m, F: 12 m, G: 13.8 m, H: 15.6 m. Thus, a total of 3321 samples were taken, each using two dredges, corresponding to 6642 sampled points over 7 years, and around 250 sampled stations per survey. The location of all samples was similar in every survey and all depths were sampled uniformly along the coast. Once on board, bivalves were separated from the remaining species, taken into the laboratory for identification to species level, counting and measurement. From each station, the dredge showing maximum abundance was used for further analysis, in order to represent maximum diversity. To summarize global trends across the geographical area, the coast was divided into three sectors: WBarl (from $9.00^{\circ} \mathrm{W}$ to $8.42^{\circ} \mathrm{W}$ longitude), EBarl (from $8.42^{\circ} \mathrm{W}$ to $7.88^{\circ} \mathrm{W}$ longitude) and 
Sot (from $7.88^{\circ} \mathrm{W}$ to $7.3^{\circ} \mathrm{W}$ longitude).

Sediment samples were obtained during the April 2005 bivalve survey at every other station. Sediment grain size $\left(\varphi=-\log _{2}\right.$ (sieve mesh in millimetres)) and sorting coefficient were then modelled and estimated for all of the sampled area. Each station was classified according to $\varphi$ values: $-0.7<\varphi<0$, very coarse sand; $0<\varphi<1$, coarse sand; $1<\varphi<2$, medium sand; $2<\varphi<3$, fine sand; $3<\varphi<4$, very fine sand; $4<\varphi<5$, very coarse silt; $5<\varphi<5.44$, coarse silt . Sorting coefficient (IGSD, inclusive graphic standard deviation) was classified according to: $0.4<\mathrm{IGSD}<0.5$ well sorted; $0.5<\mathrm{IGSD}<0.71$ moderately well sorted; $0.71<\mathrm{IGSD}<1.0$ moderately sorted; $1<\mathrm{IGSD}<2$ poorly sorted; $2<\mathrm{IGSD}<4$ very poorly sorted. Well sorted sediments are homogeneous (i.e., constituted of similar particular sizes) and are generally associated with high-energy areas.

Three other variables were computed, the distance to the nearest river outflow, the distance to the main wastewater treatment plants and the distance to the coast line.

\subsection{Statistical analysis}

Among the large number of diversity indexes developed, Hill diversity numbers have been widely recommended due to their optimal mathematical properties and because they represent diversity and evenness (i.e., if $\mathrm{N}_{1}$ is 3 , the community is similar to a community of three equally abundant species). Thus, to quantify bivalve diversity, both Pielou's evenness, for comparability with previous studies, and Hill's diversity numbers $\left(\mathrm{N}_{0}, \mathrm{~N}_{1}, \mathrm{~N}_{2}, \mathrm{~N}_{\text {Inf }}\right)$ for effective species diversity were used . Hill's numbers used were $\mathrm{N}_{0}=$ species richness (also known as species richness ( $\mathrm{S})$, i.e. all species, rare or common, count equally); $\mathrm{N}_{1}=e^{H}$, where $H$ is Shannon's index, $-\Sigma p_{i} \ln \left(p_{i}\right) ; \mathrm{N}_{2}=1 / \mathrm{D}_{\text {Simpson, }}$, where $\mathrm{D}_{\text {Simpson }}=\Sigma p_{i}{ }^{2}$, (Simpson's index of dominance) and $p_{i}=$ relative abundance of the $i$-th species, $N_{\text {Inf }}=1 / D_{B P}$, where $D_{B P}$ is BergerParker's index of dominance, i.e. the proportion of the most common species in the community or sample, $\mathrm{D}_{\mathrm{BP}}=\mathrm{p}_{\max }$. Hill's numbers are sensitive to changes in both the rare and the common species, with the lower-order numbers giving more weight to the rarer species and the higher-order numbers giving more weight to the more common species. Thus, by using Hill's numbers of varying orders, a good estimate is obtained of the importance of rare and common species in structuring the community, i.e. equitability or evenness. To quantify evenness $\left(\mathrm{N}_{1}-1\right) /\left(\mathrm{N}_{2}-1\right)$ was used, as recommended by Alatalo . According to this author, species richness (S) should not be used because (1) we can never know if we are counting all of the species in a community and (2) this measure is strongly dependent on sample size. The averages and respective $95 \%$ CI estimated by bootstrap for each index were calculated for the two 
2005 bivalve surveys and for each environmental variable factor level: season, sediment type, depth interval and geographical area. Species accumulation curves were used (instead of summary statistics) in the cases where differences in sampling rates between factor levels would compromise the results.

For spatial (geostatistics) and time-series analysis (temporal autocorrelation and relationship with fishing effort), Hill's $\mathrm{N}_{1}\left(\mathrm{e}^{\mathrm{H}}\right)$, representing diversity, and $\mathrm{E}\left(\mathrm{N}_{2} / \mathrm{N}_{1}\right)$, representing community evenness, were used. Community indexes were calculated with the vegan library, from the R-project statistical package.

Temporal autocorrelation was estimated through the autocorrelation function (acf, autoregressive models) for mean annual diversity and by periodogram for evenness. The temporal relationships with bivalve fisheries landings and CPUE (Catch Per Unit Effort) were calculated using cross-correlation, where landings $(\mathrm{kg})$ were evaluated for Chamelea gallina, Donax trunculus and Spisula solida (main bivalve target species in the Algarve) sold in the Algarve fish auction. CPUE values are the average daily landings per boat: the sum of landings, divided by the product of the number of boats and the number of fishing days, provided by the official governmental centre (Directorate-general of fisheries and aquaculture).

Diversity mapping was done using geostatistics. In a geostatistical analysis the spatial relationships between variables are explored by computing an empirical variogram, the basic tool of geostatistics. The variogram is derived from the semi-variance of all pairs of the measured variable at locations separated by increasing distance $h$. A monotonic increase of the semi-variance with increasing distance separating the sampling locations indicates the presence of spatial autocorrelation and, hence, spatial structure in the population. In the multivariate universal kriging a global variogram to estimate the spatial model range of diversity/ evenness was computed using all surveys combined, using year as a covariate. Variograms and cross-variograms were then estimated as functions of depth for every survey and every combination of surveys. The global spatial model was then fitted by weighted least squares (WLS) to every variogram/cross-variogram for 2000-2006 surveys. Further details on multivariate geostatistical analysis can be found in Cressie, Wackernagel and Pebesma .

After determining the parameters of the spatial model for each year, universal multivariate block kriging (kriging using depth as an external trend) was used to estimate diversity/evenness over unsampled locations. The kriging estimate is the average of neighbouring densities weighted by the parameters of the spatial model . All geostatistical analysis was done using the gstat library, from the R-project statistical package.

A regression tree was done to determine the importance of each abiotic factor in bivalve diversity, using only the 2005 Spring data set, as this corresponds to the year when the sedi- 
ment was sampled (rpart library, from the R-project statistical package). In this analysis, all sediment variables (grain sediment size, sorting coefficient, skewness, kurtosis, \%gravel, $\%$ mud, \%silt), bathymetry, distance to the nearest river outflow, distance to the closest main wastewater treatment plant (WWTP), and the distance to the coast line were used as explanatory variables. Further details about the regression trees can be found in Quinn \& Keough .

\section{Results}

\subsection{Diversity indexes and curves}

Species richness (S) varied between 1 and 18 per station and diversity varied between 0 and 2.1. The most diverse assemblage corresponded to an assemblage of 8 equally abundant species ( $\mathrm{N}_{1}$ was 1-8.23 sp.station ${ }^{-1}$ and $\mathrm{N}_{2}$ was 1 to 7.53 sp. station $\left.{ }^{-1}\right)$. Assemblages were dominated by a maximum of 6 species $\left(\mathrm{N}_{\text {Inf: }}\right.$ 1-5.39 sp.station $\left.^{-1}\right)$. Hill Evenness, varied between 0.56 and 1 .

\subsection{Bivalve diversity and the environment}

There were clear trends in bivalve diversity along depth and sediment grain size gradients (Fig. 2). The number of species (S) was maximum at $4.8 \mathrm{~m}$ depth, then gradually decreased towards $16 \mathrm{~m}$ (Fig. 2a). Diversity $\left(\mathrm{N}_{1}\right)$ peaked at 3-8.4 m, with a maximum of 2.9 species. Evenness steadily increased with depth; thus, assemblages at greater depths had individuals more equitability distributed among species.

Species richness (S and N1) gradually increased from coarser to muddier sediments (decreasing mean grain size, phi) (Fig. 2b). Very coarse sand communities had on average 4 species, corresponding to two species of effective richness (N1), whereas the maximum was in very coarse silt sediments $(\Phi=4-5)$ at $S: 7.3$ species and N1=3.2. Very coarse silt-sand communities showed greater numbers of dominating species $\left(\mathrm{N}_{\text {Inf: }}: 1.8\right)$, whereas very coarse sand hosted the fewest dominants (fewer than 1.5 species). Evenness showed an opposite pattern to that of diversity, with values decreasing with decreasing grain size $\left(\mathrm{N}_{2} / \mathrm{N}_{1}\right)$. Species richness (S) and richness $\left(\mathrm{N}_{1}\right)$ were maximum in very poorly sorted sediments, although the large variability (reflected in the error bars) difficult the interpretation of the data (Fig. 2c). Poorly sorted sediments with greater grain-size heterogeneity were located in lower energy areas. Evenness was greater in moderately well sorted sediments.

The total number of species captured in each survey for all sampled years (species richness), varied from a minimum of 29 species in spring 2001 to a maximum of 54 species in 
spring 2005 (Fig. 3: a). There was no evidence for a temporal or seasonal tendency. 2005 and 2006 showed greater richness than the earlier years.

Independently on the number of samples taken (which varied slightly with the survey, thus diversity cumulative curves were used), there was no evidence for a seasonal diversity pattern. (Fig. 3b). During 2000 and 2005, spring surveys were more diverse than autumn surveys, but during 2001, 2002 and 2006 the opposite was observed. Species richness (S) varied between 29 and 54 sp.survey $^{-1}$ (see also Fig. 2a). The low values of $\mathrm{N}_{1}$ (i.e., diversity, 3.3-9.2), $\mathrm{N}_{\text {Inf }}(1.7-4.1)$ and $\mathrm{N}_{2}(2.3-6.8)$ indicate that bivalve communities were dominated by few species. Indeed, $\mathrm{N}_{1}$ (diversity) was a fourth to a tenth of $\mathrm{S}$. To reach $68-78 \%$ of the species sampled in each survey required at least 50 sites. Since 2000, a total of 75 species have been identified in the area, although in each year the maximum number of species caught never exceeded 54 (i.e. $64 \%$ of total number of species ever observed in the area). This emphasizes the importance of long-term studies when measuring diversity.

Differences between the spring and autumn surveys diversity were seldom parallel (Fig. 4a), and the pattern changed through the years, for all considered indices. Average species richness (S) varied between 4 and 6 species sample ${ }^{-1}$, although diversity $\left(\mathrm{N}_{1}=2.2-3\right.$ species) was typically half of species richness. Overall the communities were dominated by $29-41 \%$ of the species $\left(\mathrm{N}_{\text {Inf }}=1.4-2.1\right.$ species $)$, and there was no clear difference between spring and autumn surveys in terms of dominance. The year with greatest difference between spring and autumn surveys was 2006, showing a significantly greater diversity $\left(\mathrm{N}_{1}\right)$ and species richness (S) in autumn.

There were large differences in all surveys in the number of samples from each sector, i.e., 150 samples were collected in Sotavento, compared to $~ 80$ samples from EBarl and only 40 samples from WBarl. As diversity stabilised at $\sim 50$ samples (Fig. 3: b), results would be biased if only the averages across the areas were compared, thus species accumulation curves were constructed to study geographic variation in bivalve diversity (Fig. 4b). The Sotavento area usually showed greater species richness, followed by EBarl and WBarl (except during 2001 Spring, and 2005), so that there was a East-West tendency in richness. However, in terms of diversity, Sotavento area had greater diversity during 2000/2001 whereas this index was was higher in WBarl during 2002 and 2005-Spring. In general evenness was very similar for the three areas.

\subsection{Mapping diversity}

Both diversity and evenness showed strong spatial and temporal autocorrelation, thus 
mapping was done using multivariate geostatistical techniques. There was no difference in spatial models between spring and autumn; thus both seasons were combined for modelling. In the multivariate geostatistical analysis, first it was produced a global variogram of the variables in function of the temporal factor, and the global spatial model was determined. Secondly, the variograms and cross-variograms of all factor levels (in this case, a variogram per year) was produced and the global model fitted into it (the variograms were not shown for brevity). Third, the model fitted for each year was used in the estimation of the mapping grid by universal kriging. The global spatial model for diversity $\left(\mathrm{N}_{1}\right)$ was fitted with a global function and estimated as nugget $=1.47$, sill $=0.27$ and range $=5.38 \mathrm{~km}$. The global spatial model of evenness, $\left(\mathrm{N}_{2} / \mathrm{N}_{1}\right)$, was estimated as sill $=2.23 * 10^{-3}$, nugget $=6.98^{*} 10^{-3}$, and a smaller range size (range $=2.48 \mathrm{~km})$.

Maps produced using multivariate kriging successfully exhibited the main patterns of bivalve diversity and evenness over the Eastern area (i.e. EBarl and Sot; the WBarl (western part) was not included due to the patchy sampling pattern) (Fig. 5 and Fig. 6). Diversity patterns were spatially patchy and varied from year to year, except for some bits of the coast. The area between Tavira and Vila Real de Santo Antonio (VRSA: about $7.5^{\circ} \mathrm{W}$ ), the area near Quarteira (about $8.2^{\circ} \mathrm{W}$ ) and the zone off Ria Formosa (open lagoon. about $7.7^{\circ} \mathrm{W}$ and $8.0^{\circ} \mathrm{W}$ ) tended to exhibit lower diversity. Similarly, the areas showing greater diversity of bivalves throughout the years were $\sim 8.1^{\circ} \mathrm{W}$ and near Fuseta. Although no seasonal pattern was evident in any area, spring surveys appeared to show larger areas with greater diversity.

The areas showing more even communities throughout the years were around $7.5^{\circ} \mathrm{W}$ (between Tavira and VRSA), $7.7^{\circ} \mathrm{W}$ (Fuseta) and $8.2^{\circ} \mathrm{W}$ (near Vilamoura) (Fig. 6). Thus, all areas with greater evenness also showed lower diversity. The Ancão $\left(8.15^{\circ} \mathrm{W}\right)$ and all the areas off Ria Formosa showed lower diversity and lower evenness (i.e. the assemblages were dominated by few species). Overall, the maps indicated greater evenness in deeper waters, but this tendency is not so clear for diversity.

The regression tree analyses evidenced that grain size, distance to the nearest wastewater treatment plant, distance to the closest river outflow and sorting coefficient were more related with 2005 bivalve diversity (Fig. 7). Together, these factors explain 46\% of total deviance (38\% with only 10 splits considered). The unexplained deviance indicates that more factors, not considered in the current study, were important to bivalve diversity. The first split of the tree (explaining $\sim 12 \%$ of deviance) showed that greater Shannon diversities were observed where grain sizes were larger than 1.85 , i.e., from medium sand to coarser silt. 


\subsection{Relationship with fisheries}

Time series analysis demonstrated significant negative correlations between evenness and both CPUE and landings five years previously, i.e. greater CPUE or landings today would reduce evenness in 5 years (Fig. 8). Species richness was positively and significantly correlated with total bivalve landings, also five years earlier, so that greater landings today would increase species richness in five years. Diversity $\left(\mathrm{N}_{1}\right)$ was similarly correlated with Spisula solida landings two years before and with Donax trunculus landings one year before. That is, greater landings of Spisula solida and Donax trunculus appear to increase diversity two and one years afterward, respectively. Chamelea gallina was the most common species in 13-46\% of the sampled hauls, whereas Spisula solida held first rank in 10-35\% and Donax trunculus in $11-22 \%$. Overall, these three commercial species represent about 59\% of the species most often caught at our stations.

\section{Discussion}

Constable and Zacharias \& Roff considered that work is urgently required to develop regional scale (space: > $1 \mathrm{~km}$; time: > 1 years) statistical models for the ecology of macrobenthic communities. In the current study bivalve diversity changes from 2000 to 2006 in both spring and autumn off the south coast of Portugal $(\sim 130 \mathrm{~km})$ across a very fine sampling grid (every $0.8 \mathrm{~km}$ in fishable areas) was described and mapped in detail. Furthermore, spatial autocorrelation was incorporated in the analysis and accurate annual/seasonal maps of evenness and diversity were produced.

The present conclusions are limited by dredge selectivity of bivalve species. Although dredges were set up with a fine mesh size of $20 \mathrm{~mm}$ to capture smaller individuals, there is still some selectivity and diversity is underestimated. Other sampling methods (e.g. box-corer) could provide more accurate estimations of diversity, but such an intensive sampling scheme would be not feasible, either geographically or temporally. A study by Chícharo et al., (2002) to determine the effect of fishing off Lagos (Western coast of the Algarve) and Vilamoura, by sampling with quadrats sieved through $1 \mathrm{~mm}$ mesh (for macrofauna) and corers (for meiofauna) at 7-9 m depth, found 38 bivalve species, among which seven were not observed in the current study. Thus, we could expect an increase of at least $20 \%$ in the species richness, if our sampling had been done in that way. In terms of diversity index, the data are not comparable because we considered only bivalves, while most studies include other species also.

Bivalve diversity increased from coarser to finer grain sizes, but no clear trend was found with the remaining sediment variables. Sediment type can influence metabolic activity and burrowing time of bivalves. Thus, we expected an even greater influence of sediment 
type on bivalve diversity than we observed in the current work (about $10 \%$ of variability, during one survey). Over the last few decades the relations between soft-sediment species assemblages and sediment properties have been reviewed by Sanders, Gray, Rhoads, Etter \& Grassle, Snelgrove \& Butman and Constable among others, resulting in a general recognition of the primary importance of sediments in structuring marine benthic communities.

Species richness and diversity increased and evenness decreased steadily from 3.5 to 16 $\mathrm{m}$ depth. The shallowest depths are considered to be harsher environments, due to strong wave action and air exposure (tidal range about 3.5 m maximum, in the current work), among other factors. Dexter observed that the number of species increased with reduced wave action, around the world (along-shore), which correspond to less harsh environments, similar to the pattern observed in current study, although across-shore.

Furthermore, even considering all sediment variables (grain size, sorting coefficient, skewness, kurtosis, \%mud, \%silt and \%sand), depth, proximity of river outflows and water treatment stations, less than half of diversity variability was explained (46\%) in the only year for which all these data was available. Thus, other environmental variables likely influence regional-scale bivalve diversity.

Ellingsen \& Gray studied the macrobenthos community along the entire coast of Norway and found that diversity was not related with latitude or any other environmental variable considered. Dexter studying beach gradients around the world, was unable to find any relationship of diversity with latitude. On the other hand, Crame and Roy et al. observed a latitudinal cline in species richness in bivalve communities, although patterns were not very regular. No latitudinal gradient was observed, which is expected given the small range of the present work. Among 12 surveys, Sotavento area was more diverse in four of the surveys and was the richest area overall. This area is probably richer than the others not because of a longitudinal gradient, but due to its greater habitat heterogeneity than that of the Barlavento areas (WBarl and EBarl).

The location of the present study is particularly relevant in terms of ecology and diversity, because it is where the faunistic influences of three Atlantic-Mediterranean biogeographical regions (Mauritanian, western Mediterranean and Lusitanian region) intersect . Thus the south coast of Portugal hosts a mixture of species mostly tropical (from north Africa), temperate (from north Atlantic) and Mediterranean.

Bivalve diversity increased with the distance to the closest river or wastewater treatment plant (RWTS) outflow (although most RWTS outflow is into the rivers). Both produce outflow of freshwater to the sea with suspended particulate matter that is rapidly mixed in the water column due to wave action. River outflows represent the major source of nutrients to 
the coastal zones, but the extent of the outflow depends mainly on river flow regime . For example, in the Guadiana River (the largest river within the study area) maximal surface influence of suspended particulate matter was at the $10 \mathrm{~m}$ isobath . Thus, we expected a substantial influence from river-mouth proximity on bivalve diversity through increased suspended matter, additional freshwater input and sediment heterogeneity. Furthermore, part of local bivalve diversity fluctuations should be related with changes in river-flow regimes. In particular, the largest Portuguese dam (Alqueva, inaugurated during 2004) has regulated more than $80 \%$ of freshwater flow in the Guadiana estuary since 2002 . Dams are well known to decrease sedimentation in coastal waters, to change the mineral composition of transported sediment and to cause long-term effects on food-web structure and biogeochemical cycling in coastal seas . Thus, the area within the Guadiana estuary mouth is of particular long-term ecological interest.

Ria Formosa coastal lagoon (located at $8^{\circ} 02^{\prime} \mathrm{W}$ to $7^{\circ} 32^{\prime} \mathrm{W}$ longitude) is another area of particular ecological interest, impacted in numerous ways by human activity . It exchanges water with the Ocean by seven inlets, of which the main ones are Faro-Olhão and Armona. There is also a small artificial inlet at the western end, Ancão, and others near Fuseta, Tavira and Lacém . Newton \& Mudge studying nutrient dynamics in Ria Formosa found no clear differences between mean annual nutrient composition at Faro-Olhão and Armona inlets. The Gilão is the main river feeding this coastal lagoon but its influence in the coastal waters is hampered by the presence of a string of sand islands in front of it, principally Tavira and Cacela. Most inlets to Ria Formosa change their locations progressively: Ancão inlet migrates eastward about $70 \mathrm{my}^{-1}$, Armona inlet about $20 \mathrm{my}^{-1}$, Fuseta inlet $\sim 65 \mathrm{~m} \mathrm{y}^{-1}$ and Lacém migrates $\sim 110 \mathrm{~m} \mathrm{y}^{-1}$. Thus, it is difficult to infer their direct effects on the surrounding coastal areas, and the entire zone seaward of Ria Formosa is predictably one with large year-to-year variation in bivalve diversity patches.

An area with higher bivalve diversity through the years of our sampling was located from Quarteira to Ancão. Quarteira coast is part of a sedimentary circulation cell, extending from Olhos de Água (western Quarteira) to Santa Maria Cape (Culatra Island), maintained mainly due to sediments produced from cliff erosion and river sedimentary discharge, $80 \%$ of which is yielded by Quarteira river watershed. Thus, the main inflow of water in this area is due to this small watershed. So, the area between Quarteira and Ancão has no other input of freshwater and should be stable in terms of sediment, providing support to maintain greater levels of bivalve diversity.

Spatial autocorrelation in ecological data can inflate Type I errors in statistical analysis . The inclusion of geographic coordinates in regression does not deal appropriately with the 
spatial correlation problem thus these variables should be avoided as explanatory variable, since their fitting may capture the general pattern very well and mask other environmental effects . The use of multivariate, universal kriging simplified our spatial model estimation and allowed us to produce maps from years with less obvious spatial dependency . Diversity maps successfully identified the main patterns and tendencies of bivalve communities in detail. The range of the spatial model, often interpreted as patch size, was shorter for evenness than for diversity. Multivariate variogram estimation and fitting assumes a fixed range for the sampled years, i.e. the patch size would be characteristic of the variable being analysed (in this case, either diversity or evenness) and permits the modelling of years where the spatial model is not so clear.

Greater shellfish CPUE appeared to reduce equitability about five years later. Temporal autocorrelation analysis showed that Spisula solida and Donax trunculus landings influenced diversity two and one year after, respectively. Fishing particularly affects commercial species, which are generally the commonest within the communities, and their selective redrawing from the system could leave an empty ecological niche that is rapidly filled by other species, consequently increasing diversity. There has been no clear decrease in species richness through time. Fisheries impact on the benthic communities has been proved to increase with depth, so that shallow communities that were more affected by wave action, were more resilient to both fishing and natural disturbance. This may explain why we were unable to show any impact of local dredge fisheries in bivalve diversity or equitability, at a regional scale. The macrobenthic seasonal pattern in temperate seas is characterized by density maxima at the end of summer and early autumn and density minima at the end of winter and early spring . Changes in macrobenthic community species composition, abundance and diversity are primarily influenced by seasonality, through changes in sea water temperature and primary production. Previous authors found lower molluscan species richness and higher diversity during autumn/winter than during spring/summer off the Iberian Peninsula. Dauvin et al. studied the spatial structure of a macrobenthic community in a muddy-fine sand area in the English channel during spring and autumn and observed low seasonal (temporal) changes in species richness and abundance. In the present work it was evident a large fluctuation of diversity across seasons, so that the trends found in one year, may not be persistent. For example, 2000 and 2005 spring surveys showed greater diversity than the autumn ones, but this was not the case for 2001, 2002 or 2006. Thus, if only one year were studied, our conclusions would be generally applicable. This information should be considered when drawing conclusions from previous studies with sampling in one or two years only. It than emphasised that diversity studies should be done at a regional scale (at least) and necessarily take into account 
several years before any conclusions are drawn.

\section{ACKnowledgements}

The authors would like to thank all participants in the bivalve surveys, as well as posterior species identification and measuring, in particular to Alexandre Pereira. Part of this work was improved by Dr. Oscar Ferreira, from the University of the Algarve (CIACOMAR), who provided us the sediment analysis. This work was part of an MMR Post-doc program financed by Fundação para a Ciência e a Tecnologia BPD /14935/ 2004.

\section{REFERENCES}




\section{FIGURES:}

Fig. 1: Detailed location of the sampling points (grey $\times$ ), WWTP $(+)$ and main river outflow (o) in the south coast of Portugal and considered areas (on the top of the map). The sampled area within the Iberian Peninsula, in Europe.

Fig. 2: Bivalve diversity according to depth interval (a), sediment type (b) and sorting coefficient (c), along the south coast of Portugal. S: species richness (S), J: Pielou's evenness and $\mathrm{N}_{1}, \mathrm{~N}_{2}$ and $\mathrm{N}_{\text {Inf: }}$ : Hill diversity numbers and $\mathrm{E}: \mathrm{N}_{2} / \mathrm{N}_{1}$ representing evenness. Note that all surveys were combined to obtain greater information on classes with lower sample size. The symbols and confidence bars represent the average and respective bootstrap 95\%CI.

Fig. 3: Pooled survey (a) and accumulation curves (b) for bivalve species richness and diversity, along the south coast of Portugal, from seasonal surveys in 2000 to 2006 . The abscissae indicate the accumulated number of sites, i.e. samples, and have the same scale for comparability. Dotted lines represent spring surveys and continuous lines autumn surveys. Index symbols as in Fig. 2.

Fig. 4: Seasonal (a) and geographical (b) variation of bivalves along the south coast of Portugal, in 2000, 2001, 2002, 2005 and 2006. Index symbols as in Fig. 2. The symbols and the bars represent the average and respective bootstrap 95\% CI. In (b), dotted line is Sot, dashed line is EBarl and continuous line is WBarl.

Fig. 5: Kriging predictions of bivalve diversity index $\left(\mathrm{N} 1=\exp \left(\mathrm{H}^{\prime}\right)\right)$, from 2000 towards 2006 in the south coast of Portugal. For brevity the spatial models and respective variograms are not shown.

Fig. 6: Kriging predictions of bivalve evenness index $\left(\mathrm{N}_{2} / \mathrm{N}_{1}\right)$, from 2000 towards 2006 in the south coast of Portugal, for spring and autumn surveys. The spatial models and respective variograms are not shown for brevity.

Fig. 7: Regression tree of bivalve diversity, in the south coast of Portugal, during April, 2005. GrainP: grain size; sortP: sorting coefficient; rio: distance to the closest river outflow; etar: distance to the closest wastewater treatment plant; depth.m: bathymetry.

Fig. 8: Temporal cross-correlations of median diversity indices with fishing effort and landings. Significant lags are presented by the thicker bars. Landings include Spisula solida, Chamelea gallina and Donax sp. reported at the Algarve ports since 1995. 
Fig. 1
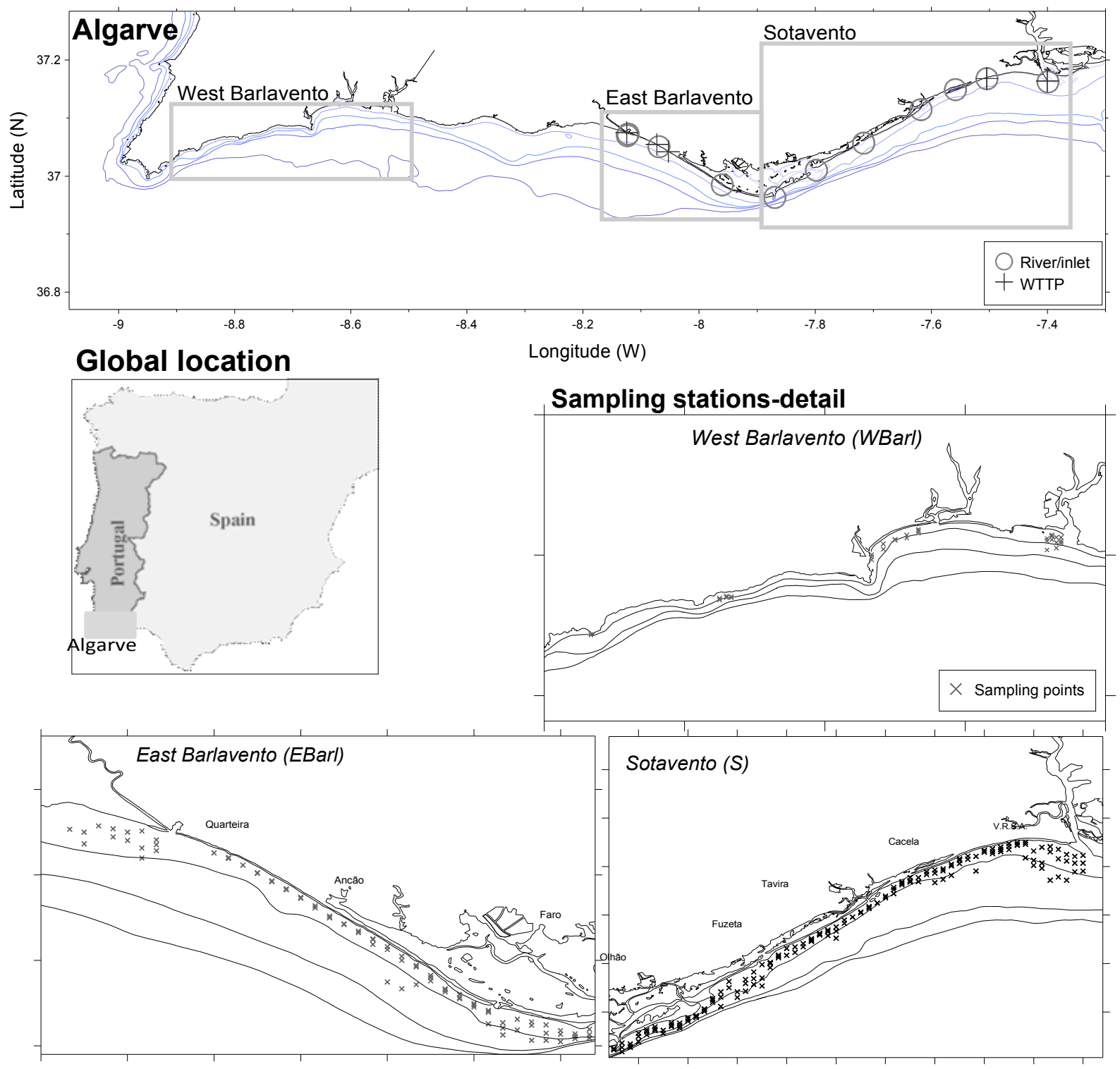
Fig. 2

(A)
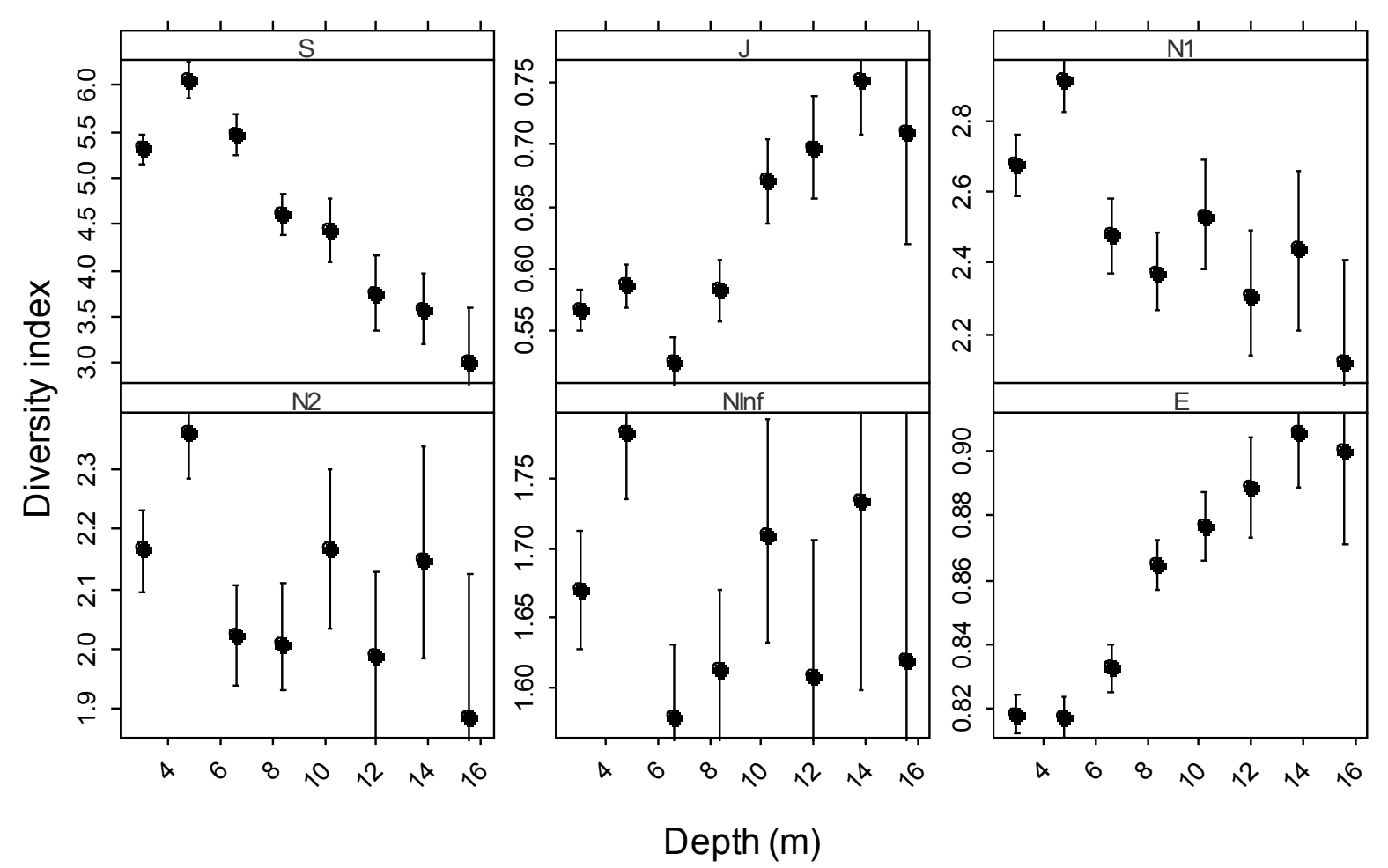

Depth (m) 
(B)

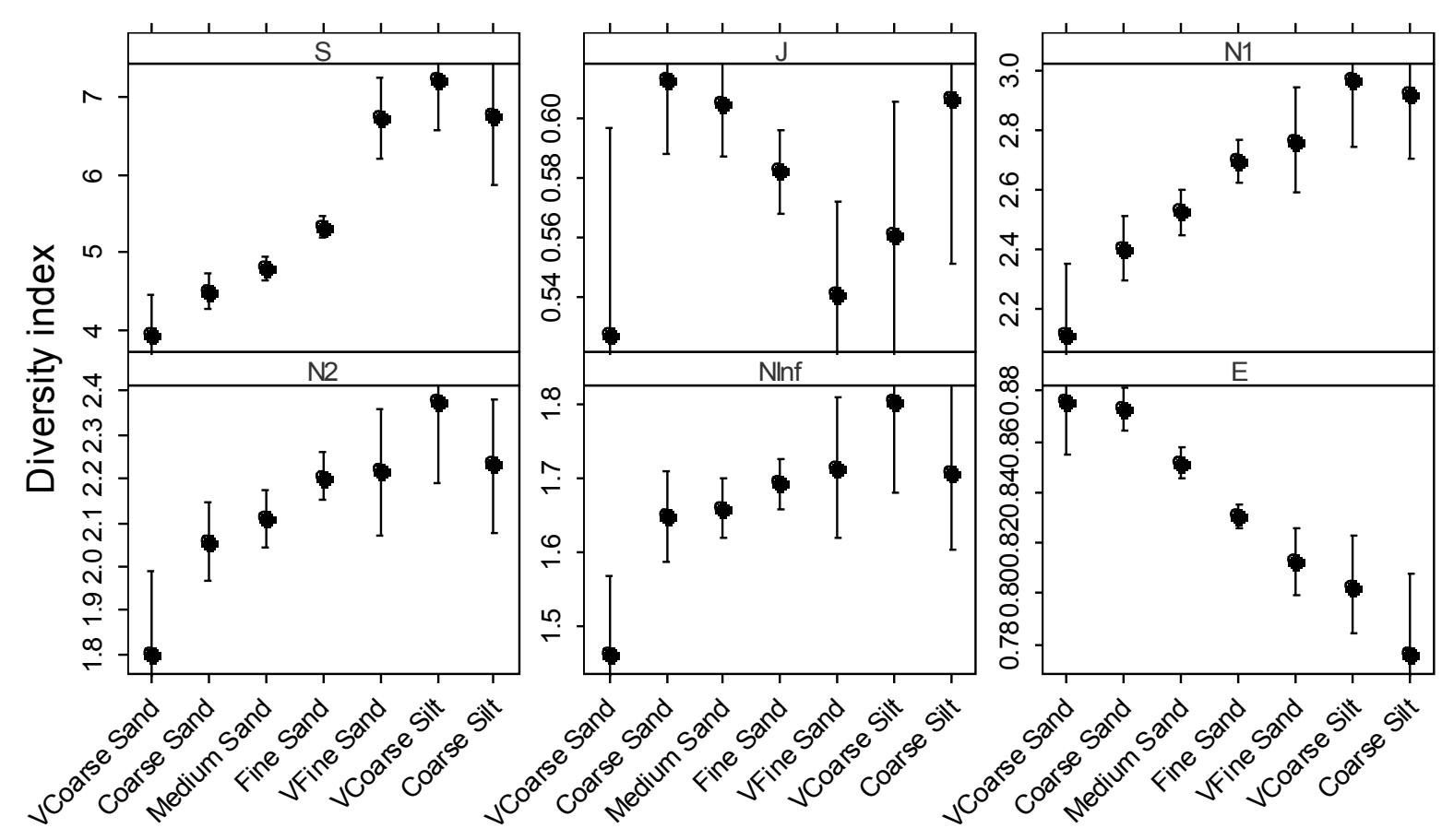

Sediment type 
(C)
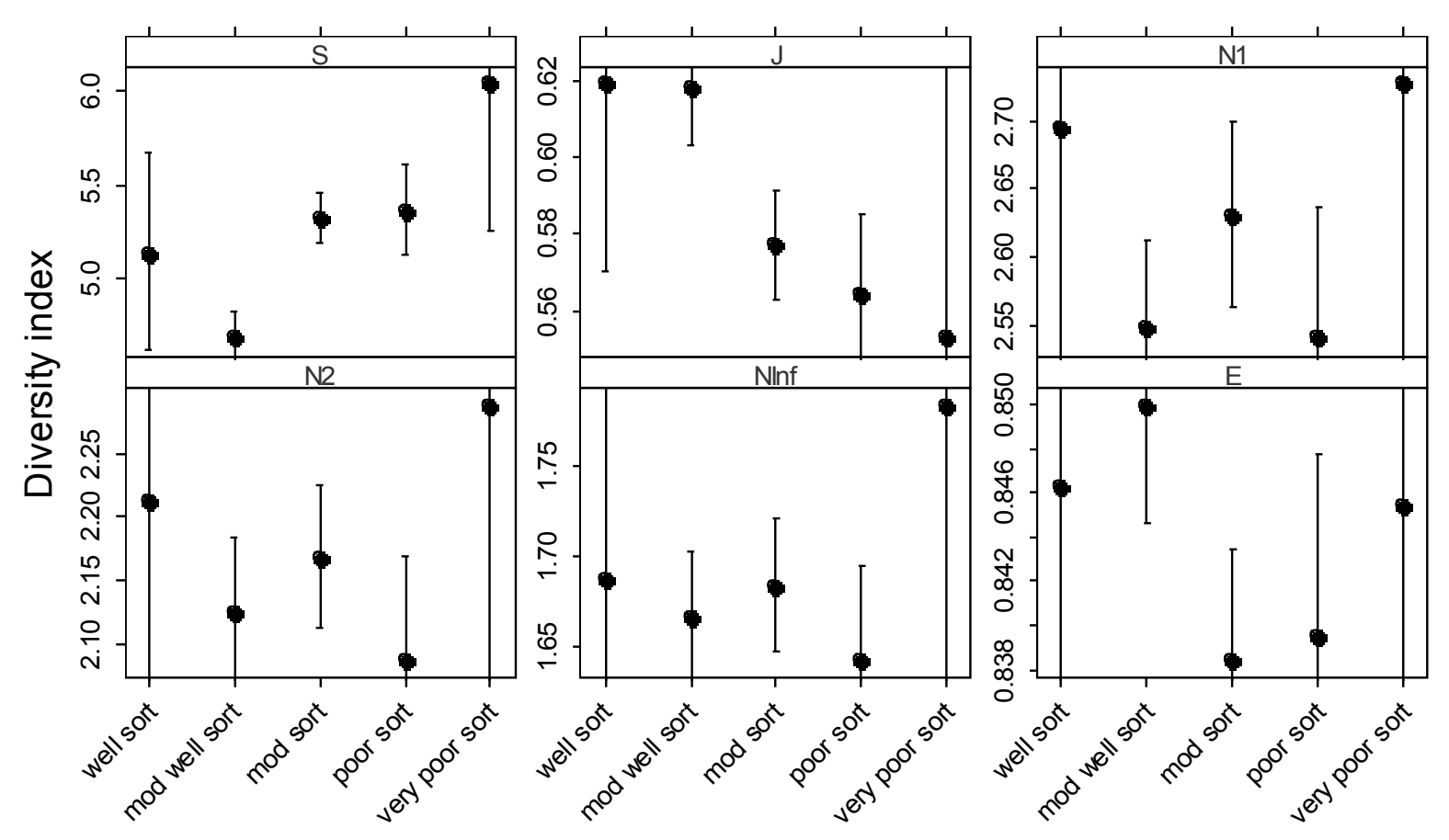

Sorting coefficient 
Fig. 3

(A)

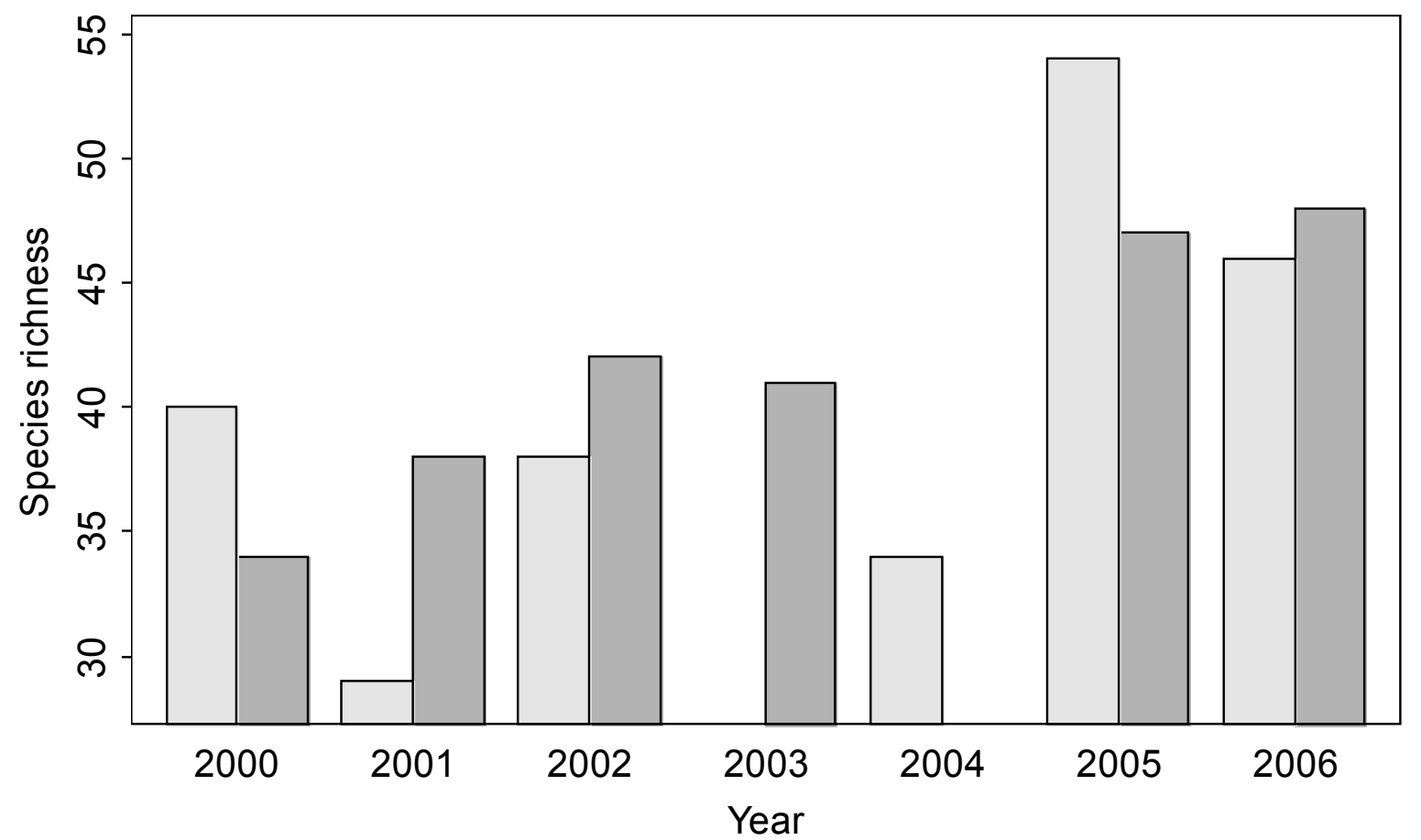

(B) 

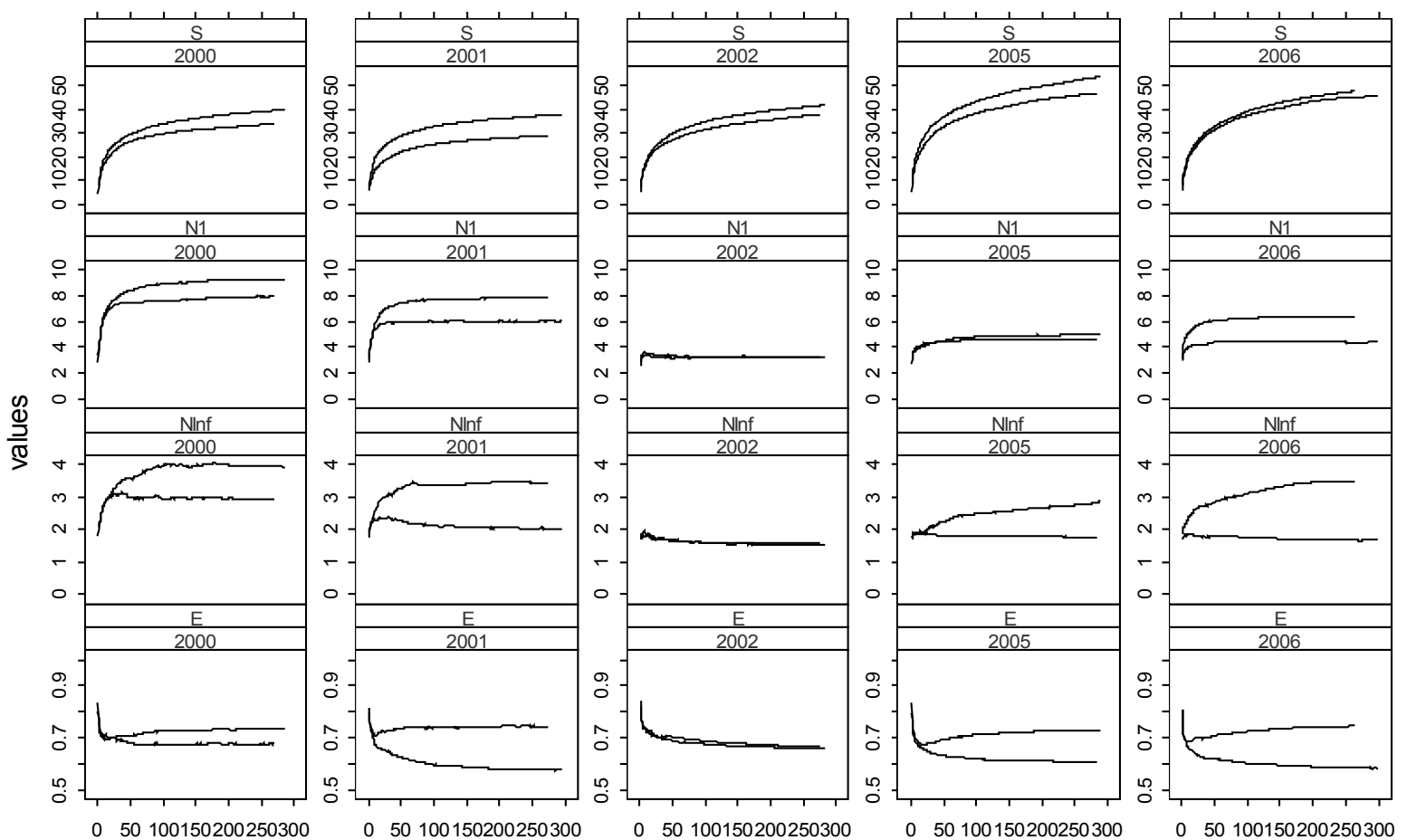

o 50100150200250300

o 50100150200250300

o 50100150200250300 sites 
Fig. 4

(A)
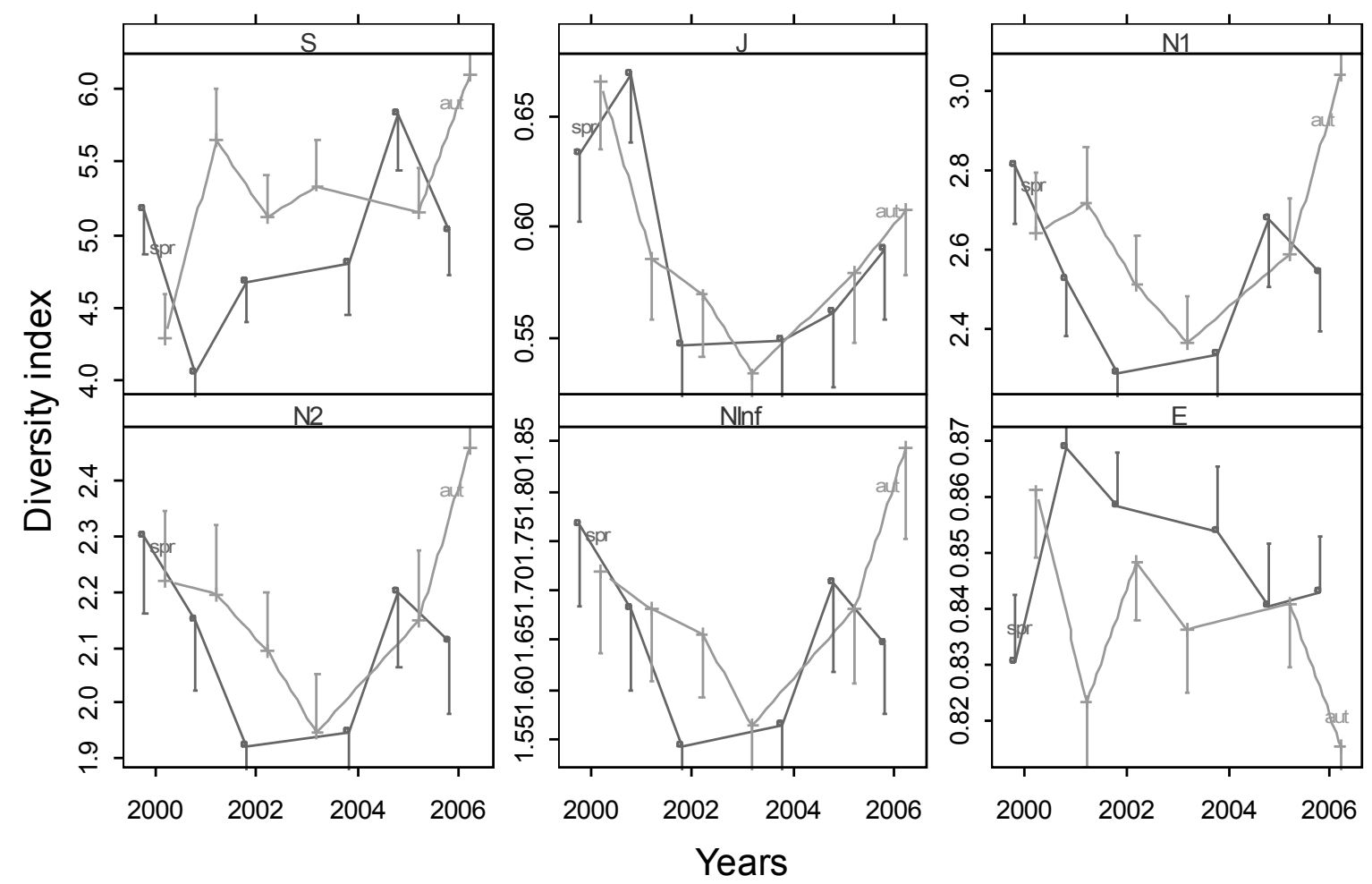

(B) 


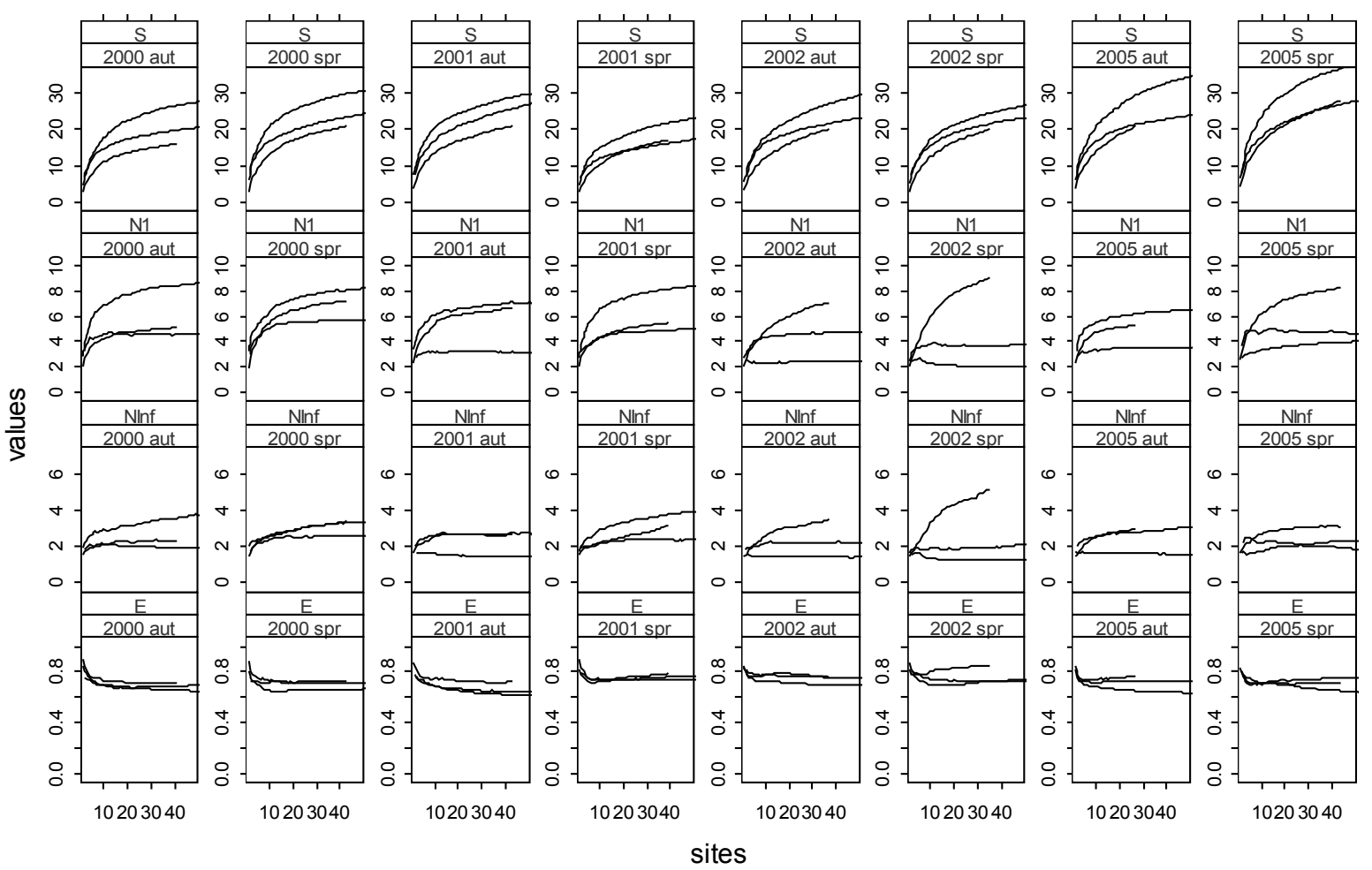


Fig. 6

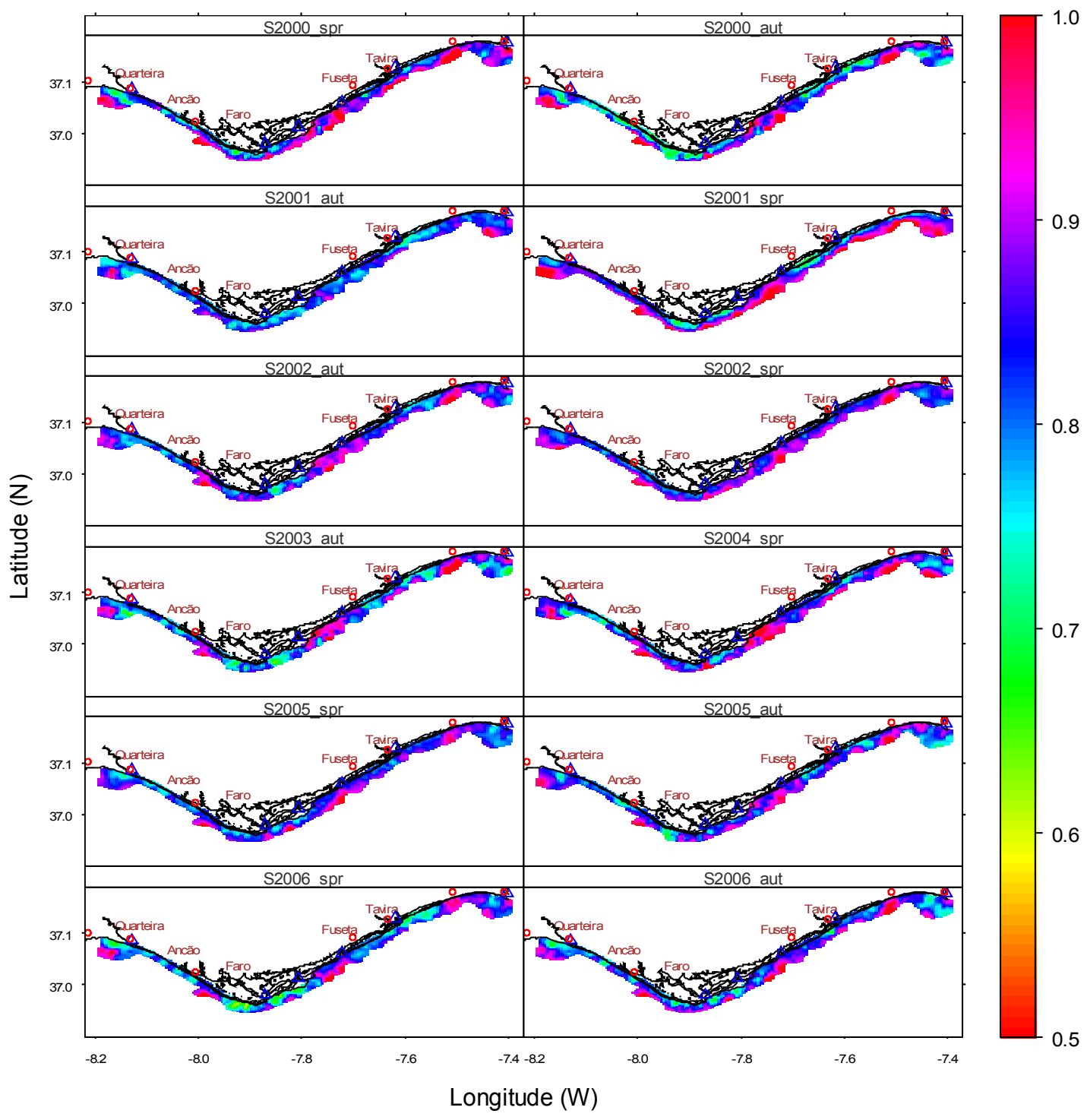

Fig. 5 


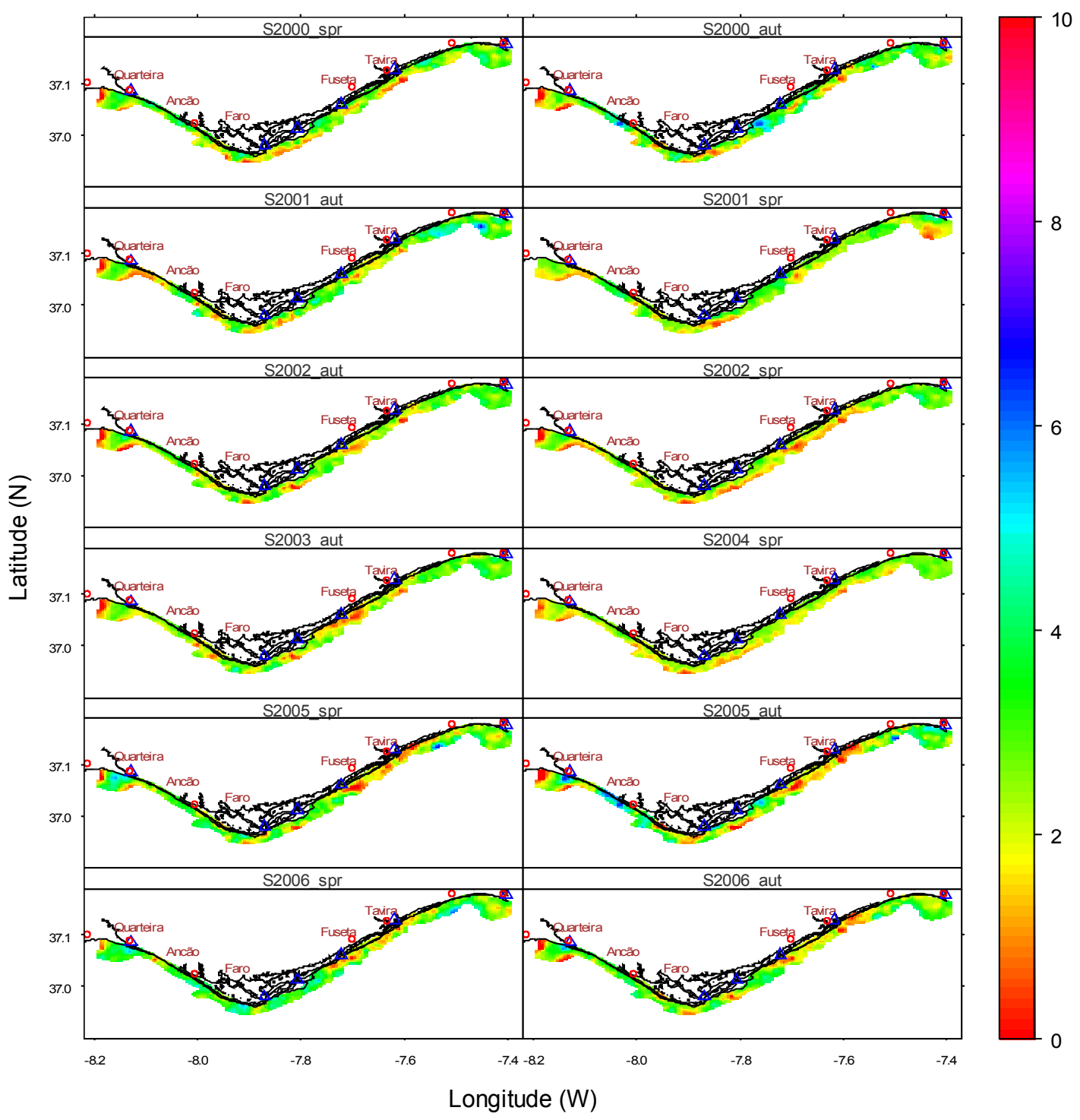


Fig. 7

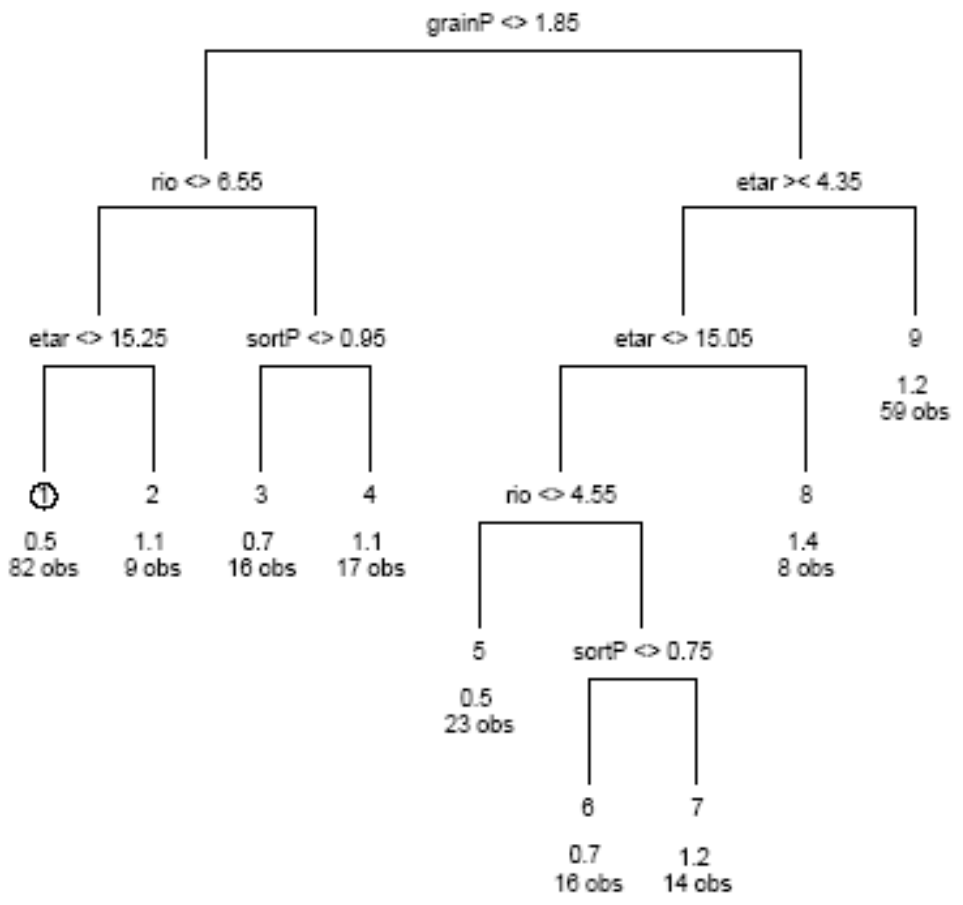


Fig. 8

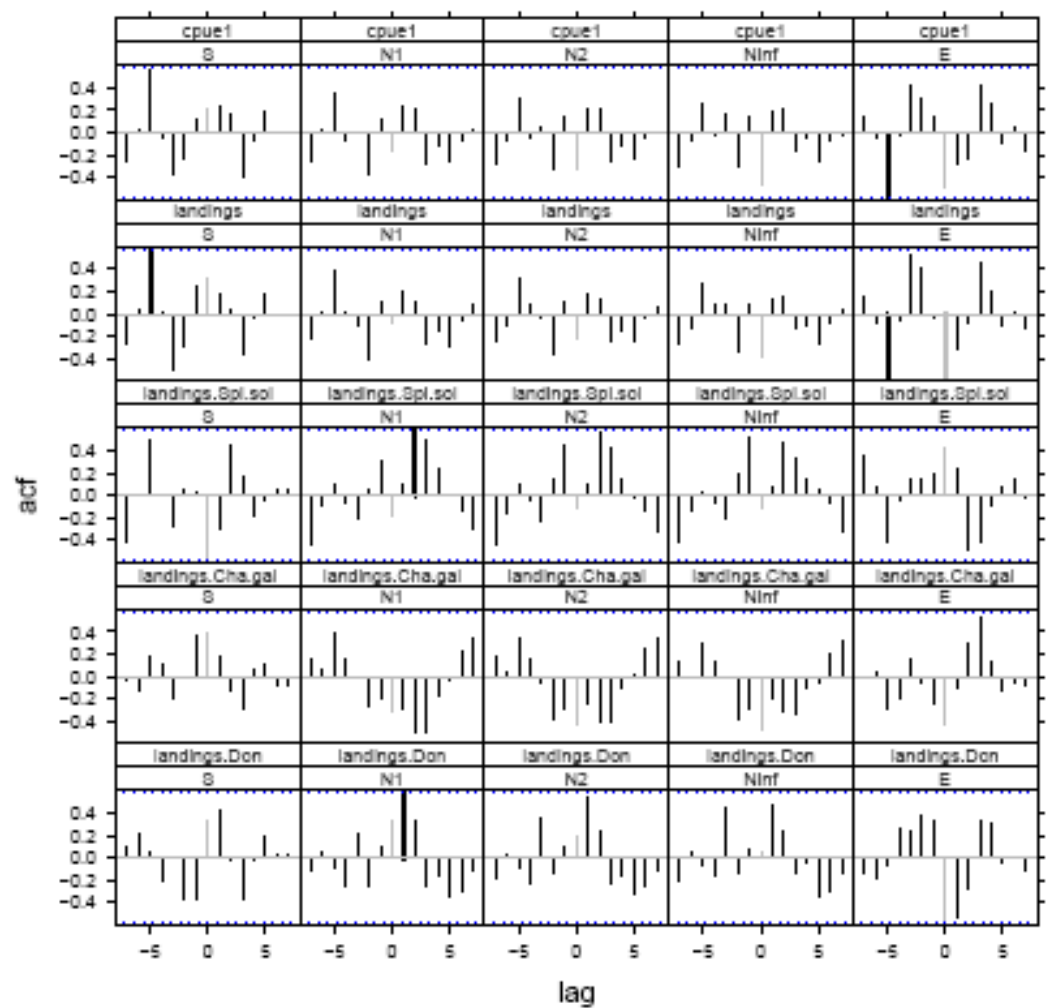

